Research Article

\title{
Enhancing Metacognitive Scaffolding and Comprehension Ability through Problem-Based Learning in an EFL Context
}

\author{
Sepideh Berenji \\ Department of English, Osku Branch, Islamic Azad University, Osku, Iran \\ Correspondence should be addressed to Sepideh Berenji; berenji@iauosku.ac.ir
}

Received 14 May 2021; Accepted 27 July 2021; Published 31 July 2021

Academic Editor: Enrique Palou

Copyright (c) 2021 Sepideh Berenji. This is an open access article distributed under the Creative Commons Attribution License, which permits unrestricted use, distribution, and reproduction in any medium, provided the original work is properly cited.

\begin{abstract}
Successful reading necessitates the application of metacognitive reading strategies, which have been proven to be effective in enhancing comprehension in EFL contexts. This quasiexperimental study, thus, aimed to implement a problem-based learning method (PBL) in an EFL instructional setting to investigate its effect on EFL learners' metacognitive reading strategies awareness and use and their comprehension ability. Two groups of students at the elementary level, one experimental $(N=40)$ and one control $(N=40)$ were selected. Their homogeneity in English proficiency was probed by Key English Test (KET). The experimental group received PBL and the control group followed the explicit lecture-based teaching method. The two groups completed preand posttest of metacognitive awareness of reading strategies inventory (MARSI) and reading comprehension. The findings based on univariate analysis of covariance indicated that the experimental group had high metacognitive reading strategies awareness and enhanced their comprehension ability to a high extent. Practitioners should pay special attention to the PBL method in EFL contexts if they want to enhance metacognitive strategies awareness and cultivate effective reading.
\end{abstract}

\section{Introduction}

To acquire professional knowledge in variety of subject fields and also to use material in different contexts, reading comprehension is considered an important skill [1]. Paris and Hamilton [2] define reading comprehension as a meaning construction process that integrates a number of coordinate cognitive processes during which the reader comprehends the text by combining textual information with his or her background knowledge. Reading comprehension can be achieved when the readers not only get the meaning of the texts by focusing on textual and background information but also implement metacognitive reading strategies [3]. The strategies readers employ while reading texts will be useful in solving comprehension problems that they may encounter [4].

Reading comprehension instruction is mainly based on teacher-centered explicit lecture-based methods [5] in most traditional EFL educational settings. Taking Iranian EFL settings into account, it becomes evident that although reading comprehension constitutes major part of the course, most learners do not have the required ability [6]. These reading comprehension courses with malfunctioning in instruction are heavily loaded with the grammar-translation method, lack of enough exposure to meaningful knowledge construction, and important of all, almost no attention to enhance metacognitive reading awareness. Therefore, the major sources of difficulty in these contexts might stem from ignoring meaningful development of metacognitive strategies awareness in reading. Today's learners must develop into good problem solvers either in educational contexts or in their life. This content-oriented decontextualized method of teaching does not have such an ability [7]. There is an urgent need for an effective teaching method to develop independence in learning, bring about engaging learning context, and increase deep, meaningful learning [8]. The new teaching method, thus, should reflect constructivism focusing on self-directing and independent learning so that learners can acquire metacognitive reading strategies meaningfully and deeply because metacognitive awareness accounts for monitoring, regulating, and evaluating the process of learning [9]. 
Metacognitive reading strategies awareness is considered one of the most important factors determining reading comprehension [10]. Metacognition has been defined by many scholars. Vandergrift [11] states that metacognition involves thinking about learning and includes directing and regulating the learning process. Zhang [4] believes that metacognitive strategies indicate reflection on thoughts. Dardjito [12] defines metacognition as a psychological ability to control the thinking process in order to achieve a particular thinking aim. Metacognitive reading awareness is also defined as the person's ability to implement his or her cognition in reading which makes them proficient readers [13].

Mokhtari, Dimitrov, and Reichard [14] divided metacognitive reading strategies into three categories, including global, problem-solving, and support strategies. Global reading strategies (GRS) are generalized strategies that are carefully planned by readers to handle, monitor reading, and set a context for reading, including setting a goal for texts, previewing reading texts, and foretelling what the reading text is about. Problem-solving strategies (PSS) are repair strategies implemented by readers to fix any problem they may encounter in understanding textual information, such as rereading the text to comprehend it better. Support reading strategies (SRS) supply support tools to enhance comprehension including the use of dictionaries.

A teaching method that can be beneficial in teaching metacognitive reading strategies is problem-based learning (PBL). PBL is a teaching method rooting in constructivism. By asking the learners to resolve authentic problems, this instructional method involves the learners with a range of ideational concepts which make them challenge knowledge they possess at the current time [15]. By encouraging learners to implement prior knowledge and knowledge from different sources, this instructional method assists learners in identifying their new learning needs and moves them toward collaboration with the other students, self-directed learning, and reflecting on self and peer learning [16, 17]. According to many scholars, including Stentoft [18], PBL meets the requirement of modern education and can enhance deep, meaningful learning, motivation, and learning commitment.

Scaffolding is implemented in PBL to a large extent to bring about high meaningful learning [19]. Scaffolding can be soft and hard [20]. Collaboration and the teacher's context specific aids, including social and cognitive congruence, are considered soft, while the static supports prepared in advance by the teacher to use in class, including paper-based cognitive instruments and computers are called hard. According to O' Grady et al. [21] and An and Cao [22], there are a variety of scaffolds such as problem definition template (PDT) and worksheets that can be classified as hard or soft based on the way they are implemented by the teacher as the facilitator; when scaffolds are made ready by the facilitator in advance to be used and accomplished by the learners mostly during self-directed studying without any help, they are classified as hard, but when these kinds of scaffolds are completed by the learners mostly in class assisted by the facilitator's cooperation and guiding questions, they are classified as soft.
There have been studies on PBL in the EFL context that have illuminated its facilitative role in enhancing meaningful learning. For example, Lin [5] and Lin [1] demonstrated the positive role of PBL in enhancing deep vocabulary knowledge and comprehension ability. In a study, Kumar and Refaei [23] showed how PBL can promote learners' critical thinking in writing in an EFL intermediate course. Baresh, Ali, and Darmi [24] implemented Hybrid PBL (HPBL) in an undergraduate English course to investigate the impact of PBL on learner's speaking ability. The results indicated that PBL involved students in learning to work autonomously and speak fluently. What is apparent in all these studies is that PBL, as MacKenzie [25] states, encourages personal construction of knowledge which results in deep, meaningful learning.

Plenty of studies have also been done on metacognitive strategies and reading comprehension ability in the EFL context. Many of these available studies have reported the facilitative role of metacognitive strategies awareness to enhance reading comprehension during the learning process in EFL instructional settings. For example, Aghaie and Zhang [26] focused on the explicit teaching of cognitive and metacognitive reading strategies. In a quasiexperimental research and by using a questionnaire adapted from Chamot and O'Malley's [27], they demonstrated that explicit teaching of cognitive and metacognitive reading strategies had a positive effect on EFL students reading ability and strategy transfer in the experimental group in comparison to the control group.

In a mixed-method study, Dabarera, Renandya, and Zhang [28] explored the effect of monitoring and metacognitive strategies awareness on ESL students reading comprehension ability in Singapore. The Metacognitive Awareness of Reading Strategies Inventory (MARSI) and the University of New South Wales, International Competitions and Assessments for Schools (UNSW ICAS) English competition Paper F were implemented to assess the students' metacognitive awareness and reading comprehension ability. To investigate ESL students experience with metacognitive strategies, a semistructured interview was also done. The results of both quantitative and qualitative findings showed a positive correlation between metacognitive strategies use and reading comprehension ability.

Fitrisia, Tan, and Yusuf [29] investigated the degree of correlation between metacognitive reading strategies use and reading ability in an EFL context. Indonesian third grade students in a secondary school participated in the study. Two standardized English reading comprehension tests and the Metacognitive Awareness of Reading Strategies Inventory (MARSI) by Mokhtari and Reichard were administered to the learners. The findings indicated a weak positive correlation between metacognitive reading strategy awareness and reading ability. Fitrisia et al. [29] indicated that the learners had high mean scores in reading metacognitive strategies awareness but low mean scores in reading comprehension. They believed that the learners could not apply the metacognitive reading strategies they know while reading EFL texts; it implies raising the awareness of reading strategies in the classroom explicitly to improve the students' proficiency in reading comprehension. 
Tavakoli and Kosha [30] investigated the impact of explicit metacognitive strategy instruction on reading comprehension and self-efficacy among EFL university students in a mixed-method study. Two classes were randomly selected as the experimental and control groups. The experimental group received explicit instruction, while the control group did not receive any instruction regarding metacognitive strategies. Survey of Reading Strategies, Motivated Strategies for Learning Questionnaire, a reading comprehension test, and semistructured interview were implemented to gather data. The results of the study revealed that the experimental group displayed greater achievement in both reading comprehension and self-efficacy.

Albazi and Shukri [31] researched the impact of explicit metacognitive strategy training on the reading comprehension of EFL female students. In this pretest-posttest control group design research, they implemented MARSI and reading comprehension tests as instruments to gather data. The findings of the study indicated a positive impact of explicit instruction on EFL learners' metacognitive reading strategies awareness and comprehension ability.

In a mixed-method study, Roohani, Sabzeali, and Mirzaei [32] intended to investigate metacognitive strategies implemented by more or less proficient English universality students in reading comprehension. As instruments, the Survey of Reading Strategies and the test of TOEFL reading proficiency were administered to students. Think-aloud tasks were also used to explore how students use metacognitive reading strategies. The findings indicated that there were significant differences among more and less proficient EFL learners in implementing metacognitive strategies. The metacognitive strategies were used by more proficient learners highly frequently in comparison to less proficient learners. In addition, proficient readers preferred implementing problem-solving strategies followed by global strategies, while less proficient learners preferred using problem-solving strategies followed by support strategies. The results of think-aloud tasks also revealed that the quality of using metacognitive reading strategies was different among more and less proficient readers.

Bang [33] investigated the metacognitive reading strategies implemented by gifted students in L1 and L2 in the English language. For this purpose, metacognitive awareness of reading strategies inventory (MARSI) and the Survey of Reading Strategies (SORS) was implemented by Mokhtari and Sheorey [34]. The results of the study indicated that students used global and support strategies equally in L1 and L2 while they implemented the problem-solving strategies in $\mathrm{L} 2$ reading more than $\mathrm{L} 1$ reading.

In a mixed-method research, Dardjito [12] explored the degree of correlation between metacognitive reading strategies awareness and reading comprehension ability among first-year Indonesian university students in an EFL setting. Paraphrasing recall protocol and metacognitive reading awareness inventory were used as instruments to gather data. The results of the study indicated no positive correlation between metacognitive strategy use and reading comprehension ability.
Diliany and Cahyono [10] researched metacognitive reading strategies awareness and metacognitive reading strategies use in an EFL context. This study also compared the metacognitive reading strategies implemented by EFL female and male students. The data were collected using the questionnaire of the Metacognitive Awareness of Reading Strategy Inventory [14]. The results of the study indicated that all of the EFL students had high metacognitive reading awareness, denoting high metacognitive reading strategies use. The findings also indicated no significant difference among male and female students in using metacognitive reading strategies and their subscales.

As the research literature indicates, varieties of studies have been done on metacognitive reading strategies awareness and reading comprehension ability in EFL contexts. Most of these studies focused on the kinds of metacognitive reading strategies implemented by learners and explicit instruction of these strategies to the learners in EFL contexts, including [26, 29-32] since, as scholars like Carrell [35] believe, metacognitive strategies and explicit instruction of these strategies could enhance metacognition and reading comprehension ability. What is lacked in all these studies is the undeniable and important role of students as whole learners. According to Lin [1], when learners attempt to challenge their current knowledge and find their own learning problems and new learning needs and try to construct knowledge through self-directed learning and collaboration, they can achieve deep, meaningful learning. By considering the importance of metacognitive reading strategies in comprehension, a new constructive teaching method must be applied to encourage deep and meaningful construction of knowledge rather than teacher-centered explicit instruction. To the best knowledge of the researcher, there have been few studies, if any, investigating the impact of PBL on metacognitive reading strategies awareness and use. To fill the gap in literature and to demonstrate the instructional effectiveness of PBL, this research is intended to investigate the effect of PBL in enhancing EFL students' metacognition in order to increase comprehension ability and aims to compare it with the control group where the focus is on explicit lecture-based instruction. For this purpose, the following research questions have been developed:

(1) Does PBL have any significant effect on enhancing EFL students' metacognitive reading strategies?

(2) Does PBL have any significant effect on EFL students reading comprehension ability?

\section{Materials and Method}

2.1. Participants. Male and female undergraduate senior students $(N=120)$ majoring in engineering courses were initial participants in this research. The students' age range was 19-30. Based on the results of the Key English Test (KET), 98 students met the criterion of one standard deviation $(\mathrm{SD}=11.05)$ above and below the mean $(M=28.30)$. After selecting a pilot group $(N=18)$, one experimental 
$(N=40)$ and one control group $(N=40)$ were chosen. Convenience sampling was implemented in this study. To internalize metacognitive reading strategies, the PBL group received a problem-based learning method and the control group followed the explicit lecture-based method. Based on an interview with students, their background knowledge in English was limited to restricted hours of instruction at high school.

2.2. Materials. Key English Test (KET), a proper exam to test the English proficiency level of learners at the elementary level, was applied to measure EFL students' homogeneity in reading and writing proficiency. Four sections, including listening, speaking, reading, and writing, exist in this ESOL test. Listening and Speaking sections were not administered to the learners due to some practical difficulties in this study. There are 60 possible marks in reading and writing sections containing nine parts. The reliability of this test was calculated to be .73 based on Kuder-Richardson Formula. Consulting four experienced EFL university professors, the content validity of the test was assured.

MARSI (Metacognitive Awareness of Reading Strategies Inventory) was applied in this research to investigate EFL learners' level of metacognitive reading strategies awareness and use in both the PBL and control groups. This test was developed by Mokhtari, Dimitrov, and Reichard [14]. MARSI contains 15 items measuring learners' metacognitive reading strategies awareness and use while reading academic or school-related materials. The items in this test are divided into three subscales, including global reading strategies (five items), problem-solving strategies (five items), and support reading strategies ( 5 items). The learners are required to rate all the items based on the given fivepoint Linkert-Scale Type. Due to the proficiency level of the learners, this questionnaire was translated into Persian. The content validity of the questionnaire was ensured by consulting three experienced EFL teachers at the university and then its reliability was calculated through Cronbach's alpha formula to be .92 .

To investigate the EFL learners' reading comprehension ability in both the PBL and control groups, reading comprehension pre- and posttest was implemented. As specified by the test of KET, the proficiency level of learners was at the elementary level. In this research thus, the course book of "Select Readings: Teacher approved readings for Today's Students" [36] was implemented both in tests and instruction. This elementary-level textbook is suitable for instruction in General English courses at the university. The total score in both pre- and posttest, including 57 questions each, was 20. Its reliability was computed to be 0.97 through Kuder-Richardson's Formula, and its validity with regard to content was assured by consulting three EFL experienced teachers at the university.

Problem definition Templates (PDT) and worksheets were used as the means of hard scaffolding in the PBL group. PDT acted as a cognitive tool and made EFL learners complete a template that consisted of three columns named "What Do They Know," "What They Do Not Know," and
"What They Need to Know." This cognitive template encouraged learners to notify their preexisting knowledge with regard to metacognitive reading strategies, their new learning needs and helped them to propose an action plan to solve their learning problems. By involving PBL learners in accomplishing varieties of tasks, worksheets moved learners toward identifying and learning metacognitive reading strategies.

2.3. Procedure. The reading and writing sections of the KET were administered to all selected EFL students to investigate their homogeneity in English proficiency. A pilot study, then, was conducted to compute the reliabilities of both reading comprehension tests and the MARSI inventory. Other goals in conducting the pilot study were to ensure the learners' weaknesses in metacognitive reading strategies awareness and use (using worksheets and PDT) and to facilitate the procedures taken during treatment in the main study, especially in terms of time needed and PBL stages. The pilot study indicated that the EFL students had lots of weaknesses in identifying and using metacognitive reading strategies.

First, the reading comprehension pretest and MARSI inventory were administered to the EFL students in both the control and experimental groups to determine their preexisting knowledge in reading comprehension and metacognitive reading strategies. The PBL method was totally explained to the students in the experimental group by the teacher for two training sessions. After the treatment, the reading comprehension posttest and MARSI inventory were administered to the students to investigate the effect of the PBL method on both the learners' metacognitive reading strategies awareness and comprehension ability. Every session lasted 90 minutes. Six lessons were covered during the treatment. The scaffolds used during the study (PDT and Worksheets) were considered hard since they were prepared by the teacher in advance to be implemented mostly during self-directed studies.

2.4. Treatment in the Experimental Group. To conduct the PBL method, the EFL learners were categorized into small groups of five and went through PBL stages. In every reading text, a true-to-life problem was presented to the learners to solve by comprehending the text. An instance can be given like the following:

"In everyday life, people undergo intense stress due to the varieties of reasons. This overstress can have lots of negative impact on their success and normal process of life. To relieve stress, what should people do?"

In the second step, prereading and reading, the learners, first read and discussed the presented problem in groups to understand and know what kinds of information they should look for within the text. The teachers then gave them the reading text. To find the answer to the problem, the teacher, as the facilitator, asked the learners to read the text and talk about the metacognitive reading strategies they implement to comprehend the text. For this purpose, PDT was given to each group to complete taking metacognitive 
reading strategies into account. In the first column, they were asked to write what they know about metacognitive reading strategies based on their prior background knowledge. In the second column, they wrote what they do not know with regard to reading strategies and in the last column, they wrote what they need to know. PDT helped the learners to contextualize and designate their learning goals and moved them toward putting forward an action plan to achieve learning objectives, the ultimate goal in the first and second phases. The time needed to complete phases one and two was about 60 minutes.

The third phase of PBL involved the learners in selfdirected learning. The teacher introduced varieties of sources, including dictionaries and the Internet to supply extra instructional support during self-directed learning. The PDT, which was completed in the class, was asked to be reviewed at home to organize the learners' thoughts. To ease the learning process and also to help the learners to move step by step [21], worksheets were given to the learners to be done while self-studying. By provision of the essential cues, samples and also asking pertinent questions, worksheets moved the learners smoothly toward increasing awareness of metacognitive reading strategies and helped the learners to implement these strategies while reading the text. The teacher asked learners to bring the worksheet and PDT to the class to talk about the findings more in the class.

In the next phase, in-class presentation and discussion, the learners discussed their findings in groups and one student as the representative of each group, first, talked about the metacognitive reading strategies they have learned and strategies they have implemented to comprehend the text and, next, provided their answer or solution to the authentic problem which was presented to them before reading the text. The teacher supplied support whenever the learners faced difficulty in their explanations. This phase lasted 60 minutes. For the rest of the class, the learners were asked to do the follow-up comprehension questions in groups and then read and check their answers.

In the last phase, evaluation of the learning process, the learners implemented self and peer evaluation reports to review and assess their learning process.

2.5. Treatment in the Control Group. An explicit lecturebased instructional method was followed in the control group. The teacher, as the sole authority in the class, transferred the instructional materials to the learners. Before starting to instruct the reading texts, the teacher made an effort to teach metacognitive reading strategies explicitly to the learners every session. After clarifying the function of reading strategies, the teacher started reading the text. Implementing metacognitive reading strategies while reading the text, the teachers tried to make the learners understand the importance of these strategies in comprehension. After finishing reading the text, the teacher started asking questions about the metacognitive reading strategies and also the text to see the extent to which the learners acquired the knowledge of metacognitive reading strategies and also check the degree of their text comprehension. The students, then, were given time to ask any question they had with regard to the metacognitive reading strategies and their use. Reading and comprehending the text lasted about 90 minutes. The teacher then required the learners to answer the comprehension questions at home. In the next session, the learners were supposed to read the answers in the class, give the summary of the metacognitive reading strategies they have learned and also ask their questions.

2.6. Design and Statistical Analysis. This research followed a quasiexperimental design with a pretest-posttest, control group. There were two groups, the experimental and the control. The independent variable was PBL and the dependent variables were metacognitive reading strategies and reading comprehension.

\section{Results}

To investigate the homogeneity of the EFL students in experimental, control, and pilot groups, first, the normality of scores distribution was taken into account in KET by conducting a one-sample Kolmogorov-Smirnov. The findings indicated that the distribution of scores in pilot $D=.13$, $P>0.05$, control $D=.13, P>0.05$, and experimental $D=.13$, $P>0.05$ groups was normal. Table 1 indicates the descriptive statistics in KET.

As Table 1 indicates, the mean score in the pilot $(M=29.50, \mathrm{SD}=5.92)$, control $(M=30.05, \mathrm{SD}=7.07$, and experimental $(M=29.33, \mathrm{SD}=6.07)$ groups are close to one another. One-way analysis of variance, thus, was conducted to examine the significance of the difference in mean scores (Table 2).

According to Table 2, a one-way analysis of variance, $F$ $(2,99)=.87, P>0.05$, implies no significant and meaningful difference in mean scores. The effect size (Eta Squared) also indicates that pilot, control, and experimental groups are homogeneous in English proficiency.

Taking the first research question into account, first, the distribution of scores in MARSI pre- and posttest in both control and experimental groups was investigated by means of one-sample Kolmogorov-Smirnov. The results represent that in the experimental group, the distribution of scores in both pretest $D=.07, P>0.05$ and posttest $D=.11, P>0.05$ was normal. Considering the distribution of scores in the control group, it became evident that in both pretest $D=.13$, $P>0.05$ and posttest $D=.14, P>0.05$ scores had a normal distribution. Therefore, the significance values in all score distributions indicate that the implementation of parametric tests was acceptable.

At the next step, the EFL learners' total scores in MARSI pre- and posttest were calculated. After conducting linearity and normality tests and ensuring that there is no deviation, the equality of variance-covariance matrix was investigated. The results indicated that as $F=1.50, P>0.001$, covariance matrices of the dependent variable were equal across the control and experimental groups. Levene's Test of Equality of Error Variances was also conducted to investigate the equality of error variances. The findings designated that as 
TABle 1: Descriptive statistics in KET.

\begin{tabular}{llccc}
\hline & $N$ & Mean & Std. deviation & Std. error \\
\hline Experimental & 40 & 29.33 & 6.07 & 0.94 \\
Control & 40 & 30.05 & 7.07 & 1.11 \\
Pilot & 18 & 29.50 & 5.92 & 1.25 \\
Total & 98 & 30.00 & 6.44 & 0.63 \\
\hline
\end{tabular}

TABle 2: One-way ANOVA results.

\begin{tabular}{|c|c|c|c|c|c|c|}
\hline & Sum of squares & $\mathrm{df}$ & Mean square & $F$ & Sig. & Effect size \\
\hline Between groups & 72.63 & 2 & 35.86 & 0.87 & 0.40 & 0.01 \\
\hline Within groups & 4120.36 & 99 & 41.62 & & & \\
\hline Total & 4193.00 & 101 & & & & \\
\hline
\end{tabular}

$F=.95, P>0.05$, there was equality of error variances of dependent variable across groups. To research the effect PBL could have on EFL learners' metacognitive reading strategies awareness and use, a univariate analysis of covariance was conducted (Table 3).

According to Table 3, statistically controlling the effect of MARSI pretest scores (covariates) in both the control and experimental groups, $F=95.59, \quad P>0.05, \quad \eta^{2}=.55$ in ANCOVA indicates that there is a significant and meaningful difference between the control and experimental groups considering metacognitive reading strategies. Table 4 displays the descriptive statistics in the MARSI posttest in both groups.

According to Table 4, taking the mean scores into account, it became evident that there is a meaningful and significant difference between the two groups in metacognitive reading strategies awareness and use. The PBL group could enhance their knowledge of strategies and also their ability to use strategies to a high extent.

Regarding the second research question, first, the normality of scores distribution in reading pre- and posttest in both the control and experimental groups was considered by means of One-Sample Kolmogorov-Smirnov. The results indicated that the distribution of scores in the experimental group, in pretest $D=.82, P>0.05$ and posttest $D=.95$, $P>0.05$ and in the control group, in pretest $D=.92, P>0.05$ and posttest $D=.83, P>0.05$ was normal.

At the next step, the learners ' total scores in reading preand posttest were calculated. After conducting linearity and normality tests and ensuring that there is no deviation, the equality of variance-covariance matrix was investigated. The results indicated that as $F=2.55, P>0.001$, covariance matrices of the dependent variable were equal across the control and experimental groups. Levene's Test of Equality of Error Variances was also implemented to investigate the equality of error variances. The results indicated that as $F=1.15, P>0.05$, there was equality of error variances of dependent variable across the control and experimental groups. To probe the effect of the PBL method on EFL learners' reading comprehension ability, a univariate analysis of covariance was conducted (Table 5).

As Table 5 displays, statistically controlling the effect of reading pretest scores as covariates in both the control and experimental groups, $F=84.32, P>0.05, \eta^{2}=.52$ indicates
TABLE 3: Univariate analysis of covariance (ANCOVA) results.

\begin{tabular}{lcccccc}
\hline & Sum of squares & df & Mean square & $F$ & Sig. & Eta \\
\hline Pretest & 2.17 & 1 & 2.17 & 6.38 & 0.010 & 0.07 \\
Group & 32.54 & 1 & 32.54 & 95.59 & 0.000 & 0.55 \\
Error & 26.21 & 77 & 0.34 & & & \\
\hline
\end{tabular}

TABle 4: Descriptive statistics in posttest.

\begin{tabular}{lcccc}
\hline \multirow{2}{*}{ Group } & \multirow{2}{*}{ Mean } & \multirow{2}{*}{ Std. error } & \multicolumn{2}{c}{$95 \%$ confidence interval } \\
& & & Lower bound & Upper bound \\
\hline PBL & 3.97 & 0.09 & 3.78 & 4.16 \\
Control & 2.67 & 0.09 & 2.48 & 2.85 \\
\hline
\end{tabular}

TABLE 5: Univariate analysis of covariance (ANCOVA) results.

\begin{tabular}{lcccccc}
\hline & Sum of squares & df & Mean square & F & Sig. & Eta \\
\hline Pretest & 168.20 & 1 & 168.20 & 40.26 & .000 & 0.34 \\
Group & 352.25 & 1 & 352.25 & 84.32 & .000 & 0.52 \\
Error & 321.67 & 77 & 4.17 & & & \\
\hline
\end{tabular}

that there is a meaningful and significant difference in both groups regarding reading comprehension ability. The PBL group was able to enhance comprehension ability to a high extent. Table 6 represents the descriptive statistics in reading posttest in both groups.

According to Table 6, considering the mean scores, it became evident that there is a meaningful and significant difference between the two groups in comprehension ability. The PBL group could improve their comprehension ability to a great extent.

\section{Discussion}

This research was an attempt to investigate the effect PBL had on students' metacognitive reading strategies awareness and use and reading comprehension ability. The findings for the first and second research questions represented high positive impact of PBL on EFL learners ' metacognitive reading strategies awareness and use and also their comprehension ability in comparison to the control group. The results of this study are in line with the results of researches which indicates that instruction can enhance learners' 
Table 6: Descriptive statistics in posttest.

\begin{tabular}{lcccc}
\hline \multirow{2}{*}{ Group } & \multirow{2}{*}{ Mean } & \multirow{2}{*}{ Std. error } & \multicolumn{2}{c}{$95 \%$ confidence interval } \\
& & & Lower bound & Upper bound \\
\hline PBL & 17.31 & 0.32 & 16.66 & 17.95 \\
Control & 13.11 & 0.32 & 12.47 & 13.75 \\
\hline
\end{tabular}

knowledge of metacognitive reading strategies awareness and comprehension ability $[26,30,31]$. This study is also in accord with the studies that indicate the positive impact of PBL on deep, meaningful knowledge construction $[1,23,24]$. The results in this study can be explained by the PBL theory, which indicates that deep, meaningful learning can be achieved by prompting the learners to participate in authentic problem-solving through self-directed learning, collaboration, and reflection [17, 37].

Enhanced metacognitive strategies awareness and use and also high comprehension ability in the experimental group in comparison to the control group can be clarified in this way that PBL as a constructivist teaching method accentuates learning through experience and reflection rather than memorization and parrot-like learning [38]. This method of learning in PBL initiated by encountering learners with real-life problems and goes on with setting and the following learning ends through group-working and selfdirected studying results in autonomous and deeply meaningful learning [39]. In this research, setting realistic goals through presenting real-life problems encouraged learners to pursue the acquisition of knowledge by reading texts. The use of hard scaffolds (PDT and worksheets) helped PBL students to identify their prior knowledge regarding metacognitive reading strategies and moved them smoothly toward knowledge enhancement and deep meaningful learning. Simply stated, self-determination and autonomy increased their engagement in knowledge acquisition considering metacognitive reading strategies and, as a result, increased their comprehension ability.

The first main positive factor in PBL is collaboration. $\mathrm{PBL}$ is a method that encourages learners to frequently share learning goals and try to acquire knowledge from their counterparts [40]. In this way, the increased class sociability acts as a motivational element to reduce the learners' anxiety and stress level associated with their proficiency level and consequently enhances their engagement in knowledge acquisition [41].

The second important factor is scaffolding. Scaffolding is considered an indispensable part of the PBL method to increase learners' engagement and bring about deep meaningful learning [21]. The right kind of scaffolding, especially in classes with many low achievers, acts as a needed help and support and facilitates teachers' attempt to be effective [19]. In this study, hard scaffolding systematically helped the students and paved the way for them to work independently at home during self-directed studying. PDT helped the PBL learners to identify their background knowledge with regard to metacognitive strategies, assisted them in identifying new learning goals, and also moved them toward setting action plans to achieve new instructional ends. Supplying varieties of tasks, worksheets helped the PBL learners to learn metacognitive reading strategies and apply them in different contexts. Scaffolding, thus, increased learners' involvement in the personal construction of knowledge and led to deep meaningful learning and increased their comprehension.

The third contributing factor in PBL is self-directed learning. According to Fukuda, Sakata, and Pop [42], selfdirected learning as the main part of successful problemsolving encourages autonomy and independence, which assist learners in controlling their own learning process. Selfdirected learning along with group-working maximizes deep, meaningful learning [43].

The last contributing factor in PBL is reflection. Reflection as a self-evaluation process boosts metacomprehension, which leads to performance enhancement and efficient learning regulation [44]. In this study, reflection helped the learners to identify their points of weakness and strength with regard to metacognitive strategies and persuaded them to monitor their progress. Reflection, thus, raised their motivation to make an effort to learn more and helped them to achieve their ultimate instructional goal, high comprehension ability.

The low learning outcomes in the control group can be attributed to the explicit lecture-based instructional method. Lack of experiential and authentic learning, absence of personal knowledge construction, and imparting knowledge solely through giving lectures made learners less active and decreased their motivation to learn [45]. In this research, the students in the control group just listened to the transfer of knowledge by the teacher concerning metacognitive strategies and reading texts. They did not participate in the personal acquisition of knowledge through collaboration or self-directed learning. This passivity reduced the learners' motivation to acquire meaningful learning. In simple terms, parrot-like learning was ineffective in increasing their knowledge of metacognitive strategies and comprehension ability.

\section{Conclusion}

This research supplies empirical support for implementing $\mathrm{PBL}$ in an EFL context to enhance metacognitive reading strategies awareness and reading comprehension ability. The significance of this study lies in the fact that, due to the lack of enough empirical evidence, it explored PBL in an EFL context to manifest its efficacy in increasing metacognitive strategies awareness and their implementation to improve comprehension.

The findings in this study have several pedagogical implications in EFL instructional settings. As Weisi [6] indicates, the majority of students have problems in reading comprehension, although it constitutes the major part of the course in the EFL context. Teachers, therefore, can implement the PBL method to extend EFL learners' knowledge of metacognitive strategies and, as a result, improve their comprehension ability. Social constructivist learning must be expanded in instructional settings since it enhances effective learning. In addition, to meet the threshold level of language proficiency, especially in classes with lots of low 
achievers, teachers should make an attempt and do their best to provide the right kind of scaffolding.

While it is found that PBL has beneficial impacts in the EFL context, the limitation of the study should not be overlooked. First, due to the small sample size, the findings should be generalized to the population with alertness. Second, the results of the study cannot be generalized to learners with EFL major since the participants of the study were non-English majors. Third, to have a comprehensive outlook regarding the usefulness of scaffolding, the soft scaffold should also be taken into account.

Some fruitful recommendations can be presented to open new areas of research. Future studies are recommended to probe PBL in classes in EFL majors. Soft scaffolds were not implemented in this research due to the effectiveness of hard scaffolds in courses with many low achievers [19]. To clarify the efficacy of the different types of scaffolds in PBL, it is suggested for future studies to compare soft and hard scaffolds.

\section{Data Availability}

All the relevant data are included in the manuscript. The author can be reached for raw materials.

\section{Conflicts of Interest}

The author declares that there are no conflicts of interest regarding the publication of this paper.

\section{References}

[1] L.-F. Lin, "Impacts of the problem-based learning pedagogy on English learners' reading comprehension, strategy use, and active learning attitudes," Journal of Education and Training Studies, vol. 5, no. 6, pp. 109-124, 2017b.

[2] S. G. Paris and E. E. Hamilton, “The development of children's reading comprehension," in Handbook of Research on Reading Comprehension, S. Israel and G. G. Duffy, Eds., pp. 32-53, Rutledge, New York, NY, USA, 2009.

[3] P. Soodla, A.-L. Jõgi, and E. Kikas, "Relationships between teachers' metacognitive knowledge and students' metacognitive knowledge and reading achievement," European Journal of Psychology of Education, vol. 32, no. 2, pp. 201-218, 2016.

[4] L. Zhang, Metacognitive and Cognitive Strategy Use in Reading Comprehension, Springer, Singapore, 2018.

[5] L.-F. Lin, "The impact of problem-based learning on Chinesespeaking elementary school students' English vocabulary learning and use," System, vol. 55, pp. 30-42, 2015.

[6] H. Weisi, "Is reading comprehension of ESP program improved by explicit teaching of grammar?" The Journal of Teaching Language Skills (JTLS), vol. vol. 3, pp. 145-158, 2012.

[7] Y. H. Cho, I. S. Caleon, and M. Kapur, Authentic Problem Solving and Learning in the $21^{\text {st }}$ Century: Perspectives from Singapore and beyond, Springer, Singapore, 2015.

[8] V. Kohonen, R. Jaatinen, P. Kaikkonen, and J. Lehtovaara, Experiential Learning in Foreign Language Education. Routledge, NY and London, 2014.

[9] Y. Zhao, "Language learning on the world wide web: toward a framework of network based CALL," Calico Journal, vol. 14, no. 1, pp. 37-51, 2013.
[10] Z. Deliany and B. Y. Cahyono, "Metacognitive reading strategies awareness and metacognitive reading strategies use of EFL university students across gender," Studies in English Language and Education, vol. 7, no. 2, pp. 421-437, 2020.

[11] L. Vandergrift, “"Facilitating second language listening comprehension: acquiring successful strategies," ELT Journal, vol. 53, no. 3, pp. 557-584, 1999.

[12] H. Dardjito, "Students' metacognitive reading awareness and academic English reading comprehension in EFL context," International Journal of Instruction, vol. 12, no. 4, pp. 611-624, 2019.

[13] A. Girli and H. Öztürk, "Metacognitive reading strategies in learning disability: relations between usage level, academic self-efficacy and self-concept," Lnternational Electronic Journal of Elementary Education, vol. 10, no. 1, pp. 93-102, 2017.

[14] K. Mokhtari, D. M. Dimitrov, and C. A. Reichard, "Revising the metacognitive awareness of reading strategies inventory (MARSI) and testing for factorial invariance," Studies in Second Language Learning and Teaching, vol. 8, no. 2, pp. 219-246, 2018.

[15] T.-H. Lee, P.-D. Shen, and C.-W. Tsai, "Enhance lowachieving students' learning involvement in Taiwan's higher education: an approach via e-learning with problem-based learning and self-regulated learning," Teaching in Higher Education, vol. 15, no. 5, pp. 553-565, 2010.

[16] C. E. Hmelo-Silver, "Creating learning space in problembased learning," Interdisciplinary Journal of Problem-Based Learning, vol. 7, no. 1, pp. 24-39, 2013.

[17] W. Hung, "Problem-based learning: a learning environment for enhancing learning transfer," New Directions for Adult and Continuing Education, vol. 2013, no. 137, pp. 27-38, 2013.

[18] D. Stentoft, "From saying to doing interdisciplinary learning: is problem-based learning the answer?" Active Learning in Higher Education, vol. 18, no. 1, pp. 51-61, 2017.

[19] S. Haruehansawasin and P. Kiattikomol, "Scaffolding in problem-based learning for low-achieving learners," The Journal of Educational Research, vol. 111, no. 3, pp. 363-370, 2018.

[20] M. Nussbaum, C. Alvarez, A. McFarlane, F. Gomez, S. Claro, and D. Radovic, "Technology as small group face-to-face Collaborative Scaffolding," Computers and Education, vol. 52, no. 1, pp. 147-153, 2009.

[21] G. O’ Grady, E. H. J. Yew, K. P. L. Goh, and H. G. Schmidt, One Day, One Problem: An Approach to Problem Based Learning, Springer Science \& Business Media, , Singapore, 2012.

[22] Y. J. An and L. Cao, "Examining the effects of metacognitive scaffolding on students' design problem solving and metacognitive skills in an online environment," Journal of Online Learning and Teaching, vol. 10, no. 4, pp. 552-568, 2014.

[23] R. Kumar and B. Refaei, "“Problem-based learning pedagogy fosters students' critical thinking about writing," The Interdisciplinary Journal of Problem-Based Learning, vol. 11, no. 2, 2017.

[24] E. F. Baresh, S. M. Ali, and R. Darmi, "Using Hybrid problembased learning (HPBL) approach to enhance Libyan EFL students' engagement with English language," International Journal of Education and Literacy Studies, vol. 7, no. 2, pp. 9-20, 2019.

[25] A. Mckenzie, "“Promoting student engagement in the English as a foreign language classroom in a Japanese university," Management Theory, vol. 86, pp. 129-143, 2015. 
[26] R. Aghaie and L. J. Zhang, "Effects of explicit instruction in cognitive and metacognitive reading strategies on Iranian EFL students' reading performance and strategy transfer," Instructional Science, vol. 40, no. 6, pp. 1063-1081, 2012.

[27] A. U. Chamot and J. M. O'Malley, The CALLA Handbook: Implementing the Cognitive Academic Language Learning Approach, Addison Wesley Longman, White Plains, NY, USA, 1994.

[28] C. Dabarera, W. A. Renandya, and L. J. Zhang, "The impact of metacognitive scaffolding and monitoring on reading comprehension," System, vol. 42, no. 1, pp. 462-473, 2014.

[29] D. Fitrisia, K. E. Tan, and Y. Q. Yusuf, "Investigating metacognitive awareness of reading strategies to strengthen students ' performance in reading comprehension," Asia Pacific Journal of Educators and Education, vol. 30, pp. 15-30, 2015.

[30] H. Tavakoli and M. Koosha, "The effect of explicit metacognitive strategy instruction on reading comprehension and self-efficacy beliefs: the case of Iranian University EFL students," Porta Linguarum: revista internacional de didáctica de las lenguas extranjeras, vol. 25, pp. 119-133, 2016.

[31] S. Albazi and N. Shukri, "Evaluating the effect of metacognitive strategy training on reading comprehension of female students at KAU," International Journal of Applied Linguistics and English Literature, vol. 5, no. 3, pp. 172-183, 2016.

[32] A. Roohani, R. Sabzeali, and A. Mirzaei, "Exploring metacognitive strategies in reading academic texts among more and less proficient EFL University Students," Journal of Modern Research in English Language Studies, vol. 4, no. 4, pp. 123-142, 2017.

[33] J. Bang, "Metacognitive reading strategies in L1 and L2 among gifted students in English language," in Proceedings of the 2017 International Conference on Platform Technology and Service (PlatCon), pp. 1-4, IEEE, Busan, South Korea, February 2017.

[34] K. Mokhtari and R. Sheorey, "Measuring ESL students' awareness of reading strategies," Journal of Developmental Education, vol. 25, no. 3, pp. 2-11, 2002.

[35] P. L. Carrell, "Can reading strategies be successfully taught?" Australian Review of Applied Linguistics, vol. 21, no. 1, pp. 1-20, 1998.

[36] L. Lee, Select Readings: Teacher-Approved Readings for Today's Students, Oxford University Press, Oxford, UK, 2011.

[37] H. Rahmanpanah and A. Mohseni, "Engagement and motivation in EFL classroom: humanizing the course book or autonomy-supportive teaching climate?" Journal of Language and Translation, vol. 7, no. 1, pp. 69-88, 2017.

[38] A. A. Abu-aisheh, L. Grant, A. Hadad, and N. Sumukadas, "Fostering engineering students engagement using problembased learning and course learner agent object portfolios," International Journal of Engineering Pedagogy (iJEP), vol. 6, no. 4, pp. 45-47, 2016.

[39] L. C. Keegan, A. Losardo, and K. C. McCullough, "Problembased learning and civic engagement in undergraduate education," Communication Disorders Quarterly, vol. 39, no. 1, pp. 312-319, 2017.

[40] E. H. J. Yew and K. Goh, "Problem-based learning: an overview of its process and impact on learning," Health Professions Education, vol. 2, no. 2, pp. 75-79, 2016.

[41] X. Zhang, H. Meng, P. O. de Pablos, and Y. Sun, "Learning analytics in collaborative learning supported by Slack: from the perspective of engagement," Computers in Human Behavior, vol. 77, pp. 1-9, 2017.

[42] S. T. Fukuda, H. Sakata, and C. Pope, "Developing selfcoaching skills in university EFL classrooms to encourage out of class study time," Innovation in Language Teaching and Learning, vol. 13, no. 2, pp. 118-132, 2017.

[43] W. Hamed, A. Al Masri, M. Smadi, and H. Maharmah, "Improving reading skills through self-directed strategy among EFL students in Jordan," Global Journal of Educational Foundation, vol. 3, no. 5, pp. 199-205, 2015.

[44] A. J. Reid, G. R. Morrison, and L. Bol, "Knowing what you know: improving metacomprehension and calibration accuracy in digital text," Educational Technology Research and Development, vol. 65, no. 1, pp. 29-45, 2016.

[45] E. Jaleniauskiene, "Revitalizing foreign language learning in higher education using a PBL curriculum," Social and Behavioral Sciences, vol. 232, pp. 265-275, 2016. 